REVISTA DE DERECHO UNED, NÚM. 21, 2017

\title{
BREVE ESTUDIO COMPARADO \\ DE LA DEMOCRACIA PARTICIPATIVA EN COLOMBIA Y ESPAÑA*
}

\section{BRIEF COMPARATIVE STUDY OF PARTICIPATORY DEMOCRACY IN COLOMBIA AND SPAIN}

\author{
ALFREDO RAMÍREZ NÁRdIZ ** \\ Universidad Libre. Barranquilla Colombia. \\ aramirez@unilibrebaq.edu.co
}

Resumen: La democracia participativa es una de las áreas más destacadas del Derecho en el presente. Su estudio comparado es de gran importancia para la comprensión de las instituciones de las que se compone en cada país. El presente texto analiza la regulación, principal jurisprudencia y fundamental práctica de la democracia participativa en Colombia y España desde la aprobación de sus Constituciones de 1991 y 1978. El objetivo es determinar los puntos en común y las diferencias entre ambos países y exponer los motivos de los mismos. Se concluye que, si bien la regulación colombiana es notablemente más rica que la española, sin embargo, la práctica de ambos países es igualmente escasa, siendo los motivos similares en algunos casos (regulación exigente) y distintos en otros (situación sociopolítica).

* Este artículo es resultado del proyecto de investigación «Transformaciones democráticas y democracia participativa», del cual es investigador principal Alfredo Ramírez Nárdiz. Universidad Libre, Seccional Barranquilla.

** Doctor en Derecho por la Universidad de Alicante, España. Profesor de Derecho jornada laboral completa en la Universidad Libre, Seccional Barranquilla. Grupo «Poder Público y Ciudadanía.» Línea «Hombre, sociedad y Estado.» 
Abstract: Participatory democracy is one of the most outstanding Law areas nowadays. Its compared study has a special relevance for the better understanding of the institutions that has in each country. This paper analyses on that way the regulation, main jurisprudence and essential practice of the participatory democracy both in Colombia and Spain from the approval of their Constitutions of 1991 and 1978. The objective is to determinate the points in common, as well as the differences between both countries and to expose the reasons. It is concluded that, if Colombian regulation is notably richer than the Spanish one, however, the practice in both countries is equally limited, being the reasons similar in some cases (exigent regulation) and different in others (socio-politic situation).

Palabras clave: Democracia participativa, Colombia, España, regulación, jurisprudencia, práctica.

Keywords: Participatory democracy, Colombia, Spain, regulation, jurisprudence, practice.

Recepción original: 15/09/2017

Aceptación original: 27/10/2017

Sumario: I. Introducción. II. Regulación y práctica comparadas: 1. El referendo. 2. El plebiscito. 3. La consulta popular. 4. La iniciativa popular. 5. La revocatoria. 6. El cabildo/concejo abierto. III. Notas sobre jurisprudencia constitucional comparada. IV. Algunas motivaciones de la democracia participativa en España y Colombia. V. Conclusiones. VI. Bibliografía: 1. Doctrina. 2. Legislación. 3. Jurisprudencia.

\section{INTRODUCCIÓN}

Este texto busca evaluar de modo comparado la democracia participativa de Colombia y España. El objetivo principal es determinar la principal regulación en materia de democracia participativa en ambos países. Son objetivos secundarios valorar el desarrollo, presente y futuro, de ambas regulaciones y explicar los motivos que justifican esta situación. En última instancia se pretende valorar si la democracia participativa ha sido de utilidad, es de utilidad y puede ser de utilidad para el progreso democrático de las dos naciones.

Desde las presentes líneas ${ }^{1}$ se partirá en todo momento de considerar la democracia participativa como un conjunto de instrumentos

${ }^{1}$ Se parte en esta propuesta de la definición dada en la obra RAMírez NÁRDIZ, A. (2012) Guía práctica de la democracia participativa. Conocer la democracia participativa y aprender a usarla, Madrid: Dykinson, pág. 109. 
jurídicos (referendos, revocatorias, iniciativas populares, etc.) que se introducen en un modelo esencialmente representativo con el fin de complementarlo y al objeto de mejorarlo al incorporarle una mayor participación de los ciudadanos y un más intenso control de éstos sobre sus gobernantes ${ }^{2}$. La democracia participativa, vista así, no es ni rupturista, ni revolucionaria, como tampoco tiene una ideología determinada más allá de la propiamente democrática, no siendo su finalidad otra que la profundización en la democracia, la mejora del modelo representativo a través de una mayor implicación de la población en el mismo.

Esta opción doctrinal asumida en este artículo no pretende suponer otra cosa más allá que una propuesta académica sujeta a debate. Como sujeto a debate se encuentra incluso el propio término democracia participativa, no siendo extraño, sino, por el contrario, bastante habitual encontrar otros como democracia directa, participación ciudadana, democracia deliberativa, etc. que se acostumbran a utilizar tanto por la legislación, como por la jurisprudencia, como por la doctrina para referirse a las mismas o a similares realidades a las que se hace referencia en este artículo con la expresión democracia participativa.

El concepto de democracia participativa que se asume en estas páginas es aquel que en gran medida surge de la doctrina participacionista de finales de los años sesenta y de los setenta, particularmente del pensamiento de autores como Habermas ${ }^{3}$, esto es, un concepto fundado en la búsqueda de la corrección de unos considerados excesos elitistas del modelo democrático imperante desde el final de la Segunda Guerra Mundial. Modelo que, como bien definiría Schumpeter ${ }^{4}$, se basaba en la competencia entre élites que se disputarían la elección popular, pero que en todo caso asumirían como común un mismo sistema tanto político (democracia repre-

2 «En rigor, cuando se trata de verdaderos procesos democráticos, la democracia participativa no solo no desplaza a la representativa, sino que la complementa, situándose en un plano diferente que permite minimizar los riesgos de alejamiento entre representantes y representados, a la búsqueda de una mejor calidad de la representación [...] no existe alternativa a la democracia representativa, que es la única democracia posible, que podrá ser susceptible de mejora, de incremento de la participación, de mayor aproximación a los individuos cuya voluntad es necesariamente el punto de partida democrático de toda fabricación de la voluntad política». FERNÁNDEZ-MirANDA, C. y FERNÁNDEZ-MIRANDA, A. (2003) Sistema electoral, partidos políticos y parlamento. Madrid: Colex, págs. 28-30.

${ }^{3}$ Vide Habermas, J. (1998) Facticidad y validez. Sobre el derecho y el Estado democrático de derecho en términos de teoría del discurso. Madrid: Trotta.

${ }^{4}$ Vide Schumpeter, J. A. (1971) Capitalismo, socialismo y democracia. Madrid: Aguilar. 
sentativa), como económico (capitalismo) y que no acudirían a los ciudadanos más que a ratificar su elección. Ante esto y en la voluntad de acercar el gobierno a la población, recuperar (en palabras de Habermas) el espacio público y garantizar que serían los intereses del pueblo y no los de las élites los que se impondrían, surge la democracia participativa.

No se trata ya, por tanto, exactamente del mismo modelo que defendía Kelsen ${ }^{5}$ en el periodo de entreguerras, fundado en el intento de consolidar el parlamentarismo haciendo que los ciudadanos votaran cuantas más veces mejor para consolidar la joven democracia de masas asediada tanto por los fascismos, como por el socialismo, sino de un modelo que nace como respuesta a lo que se consideran perniciosas derivas de un modelo democrático en exceso elitista. Por ello, la moderna democracia participativa tiene algunos rasgos particulares y diferenciados respecto a las prácticas participativas de épocas anteriores. En concreto, es eminentemente local, mucho más que nacional. Sus instrumentos acostumbran a prosperar e innovar en los ámbitos municipales, mientras que su práctica resulta casi anecdótica a escala estatal ${ }^{6}$. Igualmente se sirve cada vez más de las nuevas tecnologías de la información y la comunicación para su ejerci$\mathrm{cio}^{7}$. Y en no poca medida tiene tendencia a ser promovida de abajo arriba y no de arriba abajo, circunstancia esta última que fue la habitual con los referendos y plebiscitos previos a la Segunda Guerra Mundial.

${ }^{5}$ Vide KelSEN, H. (1977) Esencia y valor de la democracia, Madrid: Guadarrama.

${ }^{6}$ Canales apunta las razones de la mayor práctica participativa local comparada con la nacional: la proximidad; la complementariedad de lo local con lo global; la diversidad, la complejidad y la pluralidad de redes políticas y sociales existentes en el nivel local; la preeminencia de lo urbano; la aparición de nuevos problemas y conflictos sociales y medioambientales; la lucha contra la inseguridad ciudadana; el debate público mayor y más intenso sobre el presupuesto local como instrumento de gobierno y de participación; la necesidad de fortalecimiento de la pertenencia e integración del ciudadano en una determinada comunidad humana y política; la generalización de la heterogeneidad social y territorial urbana; la aparición de grandes aglomeraciones urbanas; la accesibilidad de la ciudadanía a las instituciones y políticos locales; etc. Canales Aliende, J. M. (2005) La democracia participativa local, Sistema, Revista de ciencias sociales, núm. 184-185, págs. 191-201.

${ }^{7}$ «La información y la comunicación son la esencia de todo proceso participativo (Manual OCDE) y las TICs son el instrumento idóneo para ello (...) el Reglamento (UE) núm. 211/2011, sobre la iniciativa ciudadana europea (ICE), una norma revolucionaria por cuanto está pensada esencialmente para internet». Cotino HuEso, L. (2012) La regulación de la participación y de la transparencia a través de internet y medios electrónicos. Propuestas concretas. P3T Journal of public policies and territories, núm. 2, vol. 1, págs. 29-30. 


\section{REGULACIÓN Y PRÁCTICA COMPARADAS}

La Constitución española (CE) de 1978 no recoge en ningún artículo concreto la democracia participativa. Su artículo 23.1 hace una referencia genérica al derecho a la participación política, el cual se podrá ejercer directamente o mediante representantes. Para materializar dicha apelación al ejercicio directo de la participación política se regulan diversos instrumentos participativos a lo largo del articulado constitucional, pero en ningún momento de forma sistemática en un artículo específico. Así, aparecen la iniciativa legislativa popular (art. 86.3 CE) y el referendo consultivo (art. $92 \mathrm{CE}$ ) en el título III, capítulo II titulado «De la elaboración de las leyes»; el concejo abierto (art. $140 \mathrm{CE}$ ) y los referendos autonómicos (art. 151 y $152 \mathrm{CE}$ ) en el título VIII: «De la organización territorial del Estado» y en la disposición transitoria 4. ${ }^{\text {; }}$ y los referendos para la ratificación de la reforma constitucional (arts. 167-168 CE) en el título X: «De la reforma constitucional».

La Constitución Colombiana de 1991, tras indicar en su art. 1 que Colombia es una República participativa e incorporar en el art. 2 entre los fines esenciales del Estado el de facilitar la participación de todos en las decisiones que los afectan, sí recoge específicamente la democracia participativa y le da una gran importancia ${ }^{8}$. Así, en su artículo 40 (Título II: «De los derechos, las garantías y los deberes», capítulo I: «De los derechos fundamentales») cita siete mecanismos de participación de los ciudadanos en la conformación, ejercicio y control del poder político uniendo los propios de la democracia participativa y de la democracia representativa: elegir y ser elegido; participar en las elecciones, plebiscitos, referendos, consultas populares y otras formas de participación democrática; constituir partidos políticos, movimientos y agrupaciones políticas sin limitación alguna, formar parte de ellos y difundir sus ideas y programas; revocar el mandato de los elegidos en los casos y en el modo que establecen la Constitución y las leyes; tener iniciativa en las corporaciones públicas; interponer acciones públicas en defensa de la ley y la Constitución; y acceder al desempeño de funciones y cargos públicos. El artículo 103 de la Constitución de 1991 (título IV: «De la participación democrática y de los partidos políticos», capítulo I: «De las formas de participación política») enumera los instrumentos de la democracia

${ }^{8}$ Thomas-Acuña opina que, comparada con la Constitución de 1886, la Constitución de 1991 le da una especial relevancia a la democracia participativa. THOMASAcuÑa, E. (2008) Colombia: entre la crisis de la representatividad y la democracia directa. Zurich: C2D, págs. 3 y 16. 
participativa: el voto, el plebiscito, el referendo, la consulta popular, el cabildo abierto, la iniciativa y la revocación de mandato.

Los distintos instrumentos participativos a los que citan ambas Constituciones se regulan en el propio texto constitucional así como en diversas leyes de desarrollo. En el caso colombiano, las Leyes 131 y 134 de 1994, reformadas por la Ley 741 de 2002 y la Ley 1757 de 2015. En el caso español, la Ley Orgánica 2/1980, sobre regulación de las distintas modalidades de referéndum, y la Ley Orgánica 3/1984, reguladora de la iniciativa legislativa popular, reformada por la Ley Orgánica 4/2006. En detalle, esta regulación tanto constitucional como legal, configura los instrumentos participativos de la siguiente forma:

\section{El referendo}

En España se prevén tres tipos de referendos: el consultivo, el de la reforma constitucional y el autonómico. El referendo consultivo se prevé para aquellas decisiones políticas de especial trascendencia y será convocado por el rey a propuesta del presidente del gobierno, previa autorización del Congreso de los Diputados. El referendo para la ratificación de la reforma constitucional tiene dos variantes en función de la materia: para las reformas de la CE que no afecten al título preliminar, a los derechos fundamentales y al título II, se prevé en el art. $167 \mathrm{CE}$ un referendo no obligatorio que se convocará cuando en un plazo no mayor de quince días desde la aprobación de la reforma constitucional un $10 \%$ de cualquiera de las cámaras lo solicite; para las reformas totales de la CE o para aquellas que sí afecten al título preliminar, a los derechos fundamentales y al título II, el art. $168 \mathrm{CE}$ regula un referendo obligatorio que terminará el proceso de reforma constitucional; el resultado de ambos referendos es vinculante. El referendo autonómico aparece en los artículos 151 y 152 CE y su utilidad es ratificar la creación de las Comunidades Autónomas (creación que se ejecutó entre 1979 y 1983) y la ratificación de la reforma del Estatuto de Autonomía en las CCAA que en su día ratificaron el Estatuto mediante referendo. La disposición transitoria $4 .^{\text {a }}$ regula una hipotética unión de la CCAA de Navarra a la CCAA del País Vasco y la necesidad de un referendo que la ratifique.

En más de 35 años el referendo se ha practicado poco: dos referendos consultivos -sobre la incorporación a la Organización del Tratado del Atlántico Norte (OTAN), 1986 y sobre la ratificación de la Constitución Europea, 2005: ambos aprobados-, ninguno de ratifica- 
ción de la reforma constitucional, aun y las dos reformas constitucionales realizadas (1992 y 2011), y los referendos autonómicos sólo han tenido lugar en Cataluña, País Vasco, Galicia y Andalucía9 .

En Colombia el art. 3 de la Ley 134 apunta que el referendo es la convocatoria que se hace al pueblo para que apruebe (referendo aprobatorio) o rechace (referendo derogatorio) un proyecto de norma jurídica o derogue o no una norma ya vigente. En el referendo aprobatorio -art. 5- se somete un proyecto de ley, de ordenanza, de acuerdo o de resolución local de iniciativa popular, que no haya sido adoptada por la corporación pública correspondiente, a voto popular para que éste decida si lo aprueba o lo rechaza total o parcialmente. En el referendo derogatorio -art. 4- se somete una ley, una ordenanza, un acuerdo o una resolución local, en alguna de sus partes o en su integridad, a voto popular para que decida si la deroga o no, total o parcialmente. Los referendos nacionales pueden ser legales y constitucionales. El referendo constitucional requiere la iniciativa del Gobierno o el respaldo de un mínimo del 5\% del censo electoral y que el Congreso apruebe por ley su convocatoria por mayoría de los miembros de ambas cámaras. Una reforma de la Constitución por referendo requiere el voto afirmativo de la mayoría de los votantes y que estos supongan más del 25\% del electorado.

El único referendo nacional realizado en Colombia desde la aprobación de la actual Constitución fue el 25 de octubre de 2003 para reformar la Constitución en materia fiscal, económica, entes de control y corrupción. No se aprobó. Los resultados fueron negativos para el Gobierno (Presidente Uribe), pues de las quince reformas constitucionales votadas sólo se aprobó una, la relativa a la «muerte política», la que prohibía a personas condenadas por corrupción ser candidatos para cargos públicos o ser adjudicatarios de contratos públicos. Las otras catorce propuestas de reformas (sobre materias como los límites de las pensiones estatales o el congelamiento de los salarios de los funcionarios públicos) no fueron aprobadas ${ }^{10}$.

\section{El plebiscito}

No existe como tal en España, si bien se podría considerar subsumido en el referendo consultivo que regula el art. $92 \mathrm{CE}$ (pues éste puede ser no sólo sobre normas jurídicas, sino también sobre decisiones polí-

\footnotetext{
${ }^{9}$ Vide Ramírez NáRdiz, A. (2012) op. cit.

${ }^{10}$ BBC Colombia (2003) Confirmada derrota en referendo. Consultado, 02/03/2017. news.bbc.co.uk/hi/spanish/specials/2003/balance_2003/newsid_3364000/3364751.stm
} 
ticas). En Colombia se define en el art. 7 de la Ley 134 que afirma que es el pronunciamiento del pueblo convocado por el Presidente de la República mediante el cual apoya o rechaza una determinada decisión del Ejecutivo. La convocatoria debe contar con la firma de los ministros y debe versar sobre las políticas del Ejecutivo que no requieran aprobación del Congreso, excepto las relacionadas con los estados de excepción y el ejercicio de los poderes correspondientes. El Presidente debe informar al Congreso de su intención de convocar un plebiscito, las razones y la fecha en que se hará la votación, que no puede ser anterior a un mes ni posterior a cuatro meses, contados a partir de la fecha en que el Congreso reciba el informe del Presidente. El Plebiscito no puede coincidir con otra elección. Si dentro del mes siguiente a la fecha en que el Presidente informe de su deseo de realizar un plebiscito, ninguna de las dos Cámaras, por la mayoría de asistentes, ha manifestado su rechazo, el Presidente puede convocarlo. El plebiscito no puede versar sobre la duración del periodo constitucional del mandato presidencial, ni puede modificar la Constitución. El acceso de los partidos y movimientos políticos a los espacios de televisión financiados por el Estado se hace de conformidad con lo establecido para el referendo constitucional, siendo que el Gobierno tiene el mismo tiempo en televisión para expresar su opinión sobre el plebiscito. El uso de estos espacios se hace dentro de los veinte días anteriores a la fecha señalada para la votación. El pueblo decide por mayoría del censo electoral debiendo haber una participación superior al 50\% del censo electoral.

El 2 octubre de 2016 se realizó un plebiscito para ratificar los acuerdos de paz firmados entre el gobierno y la guerrilla de las FARC. Para la regulación específica de este plebiscito se aprobó la Ley Estatutaria 1806 de 2016 (agosto 24), por medio de la cual se reguló el plebiscito para la refrendación del acuerdo final para la terminación del conflicto y la construcción de una paz estable y duradera. Esta ley rebajó la participación mínima necesaria del 50\% al 13\% e hizo que el resultado de este plebiscito fuera vinculante. Con una participación de un $37 \%$ el no ganó con un $50 \%$ frente a un $49 \%$ del si ${ }^{11}$.

\section{La consulta popular}

No existe en España en el ámbito nacional, sí en el autonómico y en el municipal, siendo regulado por los Estatutos de Autonomía de

${ }^{11}$ Registraduría Nacional del Estado Civil, Plebiscito 2 de octubre de 2016, Consultado, 24/03/2017, http://plebiscito.registraduria.gov.co/99PL/DPLZZZZZZZZZZZZZZZZZ_ L1.htm 
las diferentes Comunidades Autónomas. La STC 103/2008, de 11 de septiembre, diferenció entre referendo y consulta considerando al primero como parte de la democracia directa y al segundo como parte del fenómeno participativo, caracterizando al primero como una materialización del derecho de participación política y exigiéndole una serie de requisitos que no se dan en el segundo (la votación es sobre una cuestión política, los votantes constan en el censo y se exigen las mismas garantías que en un proceso electoral representativo). La diferenciación ha sido y es en el presente bastante polémica al haberse dado casos de autonomías (País Vasco, Cataluña) que con el nombre de consulta popular han organizado o pretendido organizar lo que el Tribunal Constitucional ha considerado referendos, siendo que estos últimos sólo los puede convocar el Estado, no las autonomías.

En Colombia la define el art. 8 de la Ley 134 como la institución mediante la cual una pregunta de carácter general sobre un asunto de trascendencia nacional, departamental, municipal, de distrito o local, es sometida por el Presidente -con firma de los ministros y con aceptación del Senado-, el gobernador o el alcalde -con aceptación del consejo o la junta administrativa local-, según el caso, a la decisión de la ciudadanía. En la consulta popular nacional, el texto de la consulta se envía por el Presidente de la República al Senado para que en veinte días se pronuncie. Igualmente, el gobernador o el alcalde solicita a la asamblea, el concejo o a la junta administradora local un pronunciamiento sobre la conveniencia de la consulta en los mismos términos que la consulta nacional. Si es desfavorable, el gobernador o el alcalde no puede convocar la consulta. No se pueden hacer consultas populares sobre una modificación de la Constitución. Cuando la consulta se refiere a convocar una asamblea constituyente, las preguntas son sometidas a consideración popular mediante ley aprobada por el Congreso. La decisión de la ciudadanía en la consulta es obligatoria, pero deben ser favorables al menos la mitad más uno de los sufragios válidos emitidos y participado en la misma no menos de la tercera parte de los electores que compongan el respectivo censo electoral. Si bien no hay consultas a nivel nacional, a nivel local sí se han producido casos relevantes como la consulta popular de la localidad de Piedras (Tolima) de cara a las explotaciones mineras que se llevan a cabo en la región ${ }^{12}$.

\footnotetext{
${ }^{12}$ Garcés Villamil, M. A. y Rapalino Bautista, W. G. (2015) La consulta popular como mecanismo de participación ciudadana para evitar actividades mineras, Justicia Juris, vol. 11, núm. 1, págs. 52-62.
} 


\section{La iniciativa popular}

En España se prevé solamente la iniciativa legislativa popular. Es una iniciativa para presentar, previa obtención de 500.000 firmas, proposiciones de ley que el Congreso puede aceptar o no y que, si acepta, puede cambiar en todo lo que estime a lo largo de la tramitación parlamentaria. No pueden ser objeto de esta iniciativa aquellas materias propias de ley orgánica (derechos fundamentales, libertades públicas, régimen electoral general, estatutos de autonomía de las regiones e instituciones del Estado), tributarias, de carácter internacional, la prerrogativa de gracia o la reforma de la Constitución. Se deben recoger las firmas en un plazo de nueve meses prorrogables a doce. Transcurrido este tiempo y si no se han reunido las firmas, la iniciativa caduca. Certificadas las firmas y remitida al Congreso la iniciativa comienza la tramitación parlamentaria. La tramitación parlamentaria se realiza conforme a lo que indiquen los Reglamentos de las Cámaras. El contenido de la iniciativa puede ser modificado en su tramitación parlamentaria. Si la iniciativa popular alcanza la tramitación parlamentaria, se deben reembolsar a la Comisión Promotora los gastos generados para la recogida de firmas. Estos gastos, que deben ser justificados, tienen un límite de 300.000 euros (cantidad revisada anualmente en función del IPC). Ninguna iniciativa ha acabado convertida en ley ${ }^{13}$.

En Colombia el artículo 2 de la Ley 134 define la iniciativa popular legislativa y normativa ante las corporaciones públicas como el derecho político de un grupo de ciudadanos de presentar proyectos de acto legislativo y de ley ante el Congreso, de ordenanzas ante las asambleas departamentales, de acuerdos ante los consejos municipales o distritales y de resoluciones ante las juntas administradoras locales y demás resoluciones de las corporaciones de las entidades territoriales para que sean debatidos y así aprobados, modificados o negados por la corporación pública correspondiente. Sólo pueden ser materia de iniciativa las que sean de la competencia de la respectiva corporación. No se pueden presentar iniciativas populares en materias que sean de iniciativa exclusiva del Gobierno, de los gobernadores o de los alcaldes; presupuestales, fiscales o tributarias; relaciones internacionales; concesión de amnistía o indultos; preservación y restablecimiento del orden público. Para promover una iniciativa popular ésta debe estar suscrita por el 5\% de los ciudadanos inscritos en

${ }^{13}$ Sólo la iniciativa legislativa popular sobre reclamación de deudas comunitarias, que no fue aprobada como tal, sí que fue posteriormente subsumida en la Ley de Propiedad Horizontal de 1998. Ramírez Nárdiz, A. (2012) op. cit., págs. 56-72. 
el censo electoral si la iniciativa es de ámbito nacional y del 10\% si es de ámbito territorial inferior al nacional. Si la corporación correspondiente no aprueba la iniciativa, los ciudadanos pueden pedir la convocatoria de un referendo con el apoyo de al menos el 10\% de los ciudadanos del censo. El vocero de la iniciativa debe ser convocado a todas las sesiones en que se tramite el proyecto y ser oído en todas las etapas del trámite, así como puede apelar si la comisión respectiva se pronuncia en contra de la iniciativa popular. Cuando la respectiva corporación no dé primer debate a una iniciativa popular durante una legislatura y esta deba ser retirada, se puede volver a presentar en la siguiente legislatura. En este caso, siguen siendo válidas las firmas que apoyan la iniciativa popular y no es necesario volver a recogerlas.

La mayoría de las iniciativas no concluyen el proceso y terminan en alguna de las etapas del mismo. Ejemplos: iniciativa de 2005 de modificación del régimen constitucional de los servicios públicos domiciliarios (obtuvo casi 1.8 millones de firmas, pero no prosperó en el Congreso); iniciativa de 2006 de modificación del Decreto Ley 2535 de 1993, por el cual se expiden armas, municiones y explosivos (obtuvo casi 1.5 millones de firmas, pero no prosperó en el Congreso ${ }^{14}$.

\section{La revocatoria de mandato}

No existe en España al ser, como la mayoría de países europeos, un Estado parlamentario. Los diferentes gobernantes (Presidente del Gobierno, Presidentes de Comunidades Autónomas y Alcaldes) no son elegidos por los ciudadanos, sino por los respectivos parlamentos (Congreso de los Diputados, Asambleas de las Comunidades Autónomas y Ayuntamientos), cuyos miembros (diputados nacionales, diputados autonómicos y concejales) sí son elegidos por los ciudadanos. Dado que el gobernante no es de elección popular, no puede ser revocado por los ciudadanos, sino por aquel que le eligió, esto es, por el parlamento mediante una moción de censura.

En Colombia mediante la revocatoria los ciudadanos dan por terminado el mandato que han conferido al gobernador o al alcalde ${ }^{15}$.

${ }^{14}$ Registraduría Nacional del Estado Civil, Iniciativa legislativa y normativa, histórico de iniciativas. Consultado, 03/03/2017. www.registraduria.gov.co/-Historico-deiniciativas-.html.

${ }^{15}$ La revocatoria de mandato hay que entenderla en Colombia como consecuencia de la institución del voto programático. En este sentido, y como regula la Ley 131 de 1994, en caso de que el alcalde o gobernador no cumpla el programa electoral al cual se comprometió durante la campaña electoral, puede activarse la revocatoria por los ciudadanos. 
Debe solicitarse ante la Registraduría Nacional mediante un memorial que suscriban los ciudadanos en número no inferior al 30\% del total de votos que obtuvo el elegido (hasta 2015 era el 40\%). La revocatoria sólo puede iniciarse cuando haya transcurrido un año como mínimo desde la toma de posesión del gobernador o el alcalde. Se debe hacer la solicitud de revocación exponiendo los argumentos por los que se solicita (insatisfacción general de los votantes o incumplimiento del programa de gobierno del mandatario). Expedida la certificación que apruebe la solicitud de realizar la revocatoria, la votación se realiza en un plazo de dos meses. El mandato del gobernador o del alcalde es revocado si la votación es aprobada en el pronunciamiento popular por la mitad más uno de los votos ciudadanos que participen en la respectiva convocatoria, siempre que el número de sufragios no sea inferior al 40\% (hasta 2015 era el 55\%) de la votación válida registrada el día en que se eligió al respectivo mandatario. Si la revocatoria no tiene éxito, no puede volver a convocarse otra en el mismo mandato del gobernador o alcalde. Si tiene éxito, la remoción del mandatario es inmediata y en los treinta días siguientes se celebrarán elecciones para la elección del sustituto. Durante estos treinta días, se nombra un encargado del mismo partido del mandatario revocado para ejercer sus funciones. Apenas prosperan revocatorias: en el año 2013 hubo 35, de las que sólo 2 prosperaron ${ }^{16}$.

\section{El cabildo/concejo abierto}

En España el concejo abierto, además de por el art. $140 \mathrm{CE}$, se regula por la Ley 7/1985, de 2 de abril, reguladora de las bases del régimen local, particularmente en su art. 29. También en la 5/1985, de 19 de junio, de régimen electoral general, con las modificaciones incorporadas por la Ley Orgánica 2/2011, de 28 de enero. Importantes en la regulación del concejo abierto son los usos y costumbres del lugar. Será en defecto de los mismos, cuando el concejo abierto se regule por las leyes citadas. El concejo abierto es en la reunión en asamblea popular de los ciudadanos con derechos políticos de una comunidad pequeña, generalmente rural, sustituyendo a la asamblea representativa y siendo sus decisiones de ámbito local. En el concejo abierto el gobierno y la administración del municipio son competencia del alcalde y de una asamblea vecinal de la que forman parte todos los electores del municipio. Se organizan así los municipios de

\footnotetext{
${ }^{16}$ Registraduría Nacional del Estado Civil, Ranking de mecanismos de participación por departamentos. Consultado 04/03/2017. www.registraduria.gov.co/-Mecanismos-de-Participacion,320-.html.
} 
menos de 100 habitantes, los que tradicional y voluntariamente cuenten con este régimen de gobierno y administración y los municipios en los que este régimen sea aconsejable por su localización geográfica, por la mejor gestión de los intereses municipales o por otras circunstancias ${ }^{17}$. Las asambleas de concejo abierto han de reunirse allí donde sea costumbre, celebrando sesión ordinaria al menos una vez cada tres meses en día festivo y siendo convocadas a toque de campana, por pregón, por anuncio o por cualquier otro medio que sea tradicional en el lugar. Las decisiones deben adoptarse por mayoría de votos. Debe asistir una tercera parte de los vecinos, presentes o representados que a ello tengan derecho, no pudiendo nunca los presentes ser menos de tres. Los asuntos a decidir pueden consistir desde la aprobación de los presupuestos municipales hasta la disposición y gravamen de bienes inmuebles, pasando por el establecimiento de mancomunidades, consorcios y convenios con otros entes locales, etc. El concejo abierto es en España un instrumento participativo marginal, limitado a los ámbitos rurales.

En Colombia el cabildo abierto es la reunión pública de las asambleas departamentales, concejos distritales, municipales o las juntas administrativas locales, en la cual los habitantes pueden participar directamente a fin de discutir asuntos de interés para la comunidad. En cada periodo de sesiones deben celebrarse al menos dos sesiones para estudiar asuntos propuestos por los residentes. Estos asuntos deben ser competencia de la corporación ante la que se presenten (municipio, distrito, localidad, comuna o corregimiento). Para que un asunto sea discutido en cabildo abierto la propuesta debe estar apoyada con las firmas del 5 por mil del censo electoral. Las organizaciones civiles pueden participar, así como todo aquel que tenga interés en las materias que se traten, teniendo derecho a ser oídos el vocero de quienes solicitaron el cabildo y todos los que se inscriban con un mínimo de tres días de anticipación y presenten un resumen escrito de su intervención. Puede ser materia de cabildo abierto cualquier asunto de interés para la comunidad. No pueden serlo los proyectos de ordenanza, acuerdo o cualquier otro acto administrativo. Si la materia del cabildo afecta específicamente a una localidad, corregimien-

${ }^{17}$ Desde la LO 2/2011 el carácter obligatorio que tenía el concejo abierto para los municipios de menos de 100 habitantes pasó a ser voluntario. Así, ahora, como regla general, los municipios de menos de 100 habitantes eligen tres concejales y funcionan por el régimen común. Si desean mantener el régimen de concejo abierto, deben decidirlo la mayoría de los vecinos y los tres concejales electos. No obstante, aunque el municipio opte por el régimen común, el alcalde de los municipios de menos de 100 habitantes puede convocar el concejo abierto para decidir sobre cuestiones de especial trascendencia. Las decisiones así tomadas son vinculantes. 
to o comuna, el cabildo puede sesionar en cualquier sitio de ésta, con la presencia del respectivo concejo municipal o distrital, o la junta administradora local. Los concejos municipales o distritales, o las juntas administradoras locales, deben dar amplia difusión de la fecha, el lugar y los temas del cabildo abierto. Se debe ordenar la publicación de dos convocatorias en un medio de comunicación idóneo. Terminado el cabildo, en la semana siguiente, en audiencia pública, el presidente de la corporación debe dar respuesta escrita y razonada a los planteamientos y solicitudes de la población. El cabildo abierto puede controlar a los funcionarios locales, pues por solicitud de los promotores del cabildo o por iniciativa de los voceros, previa proposición aprobada por la corporación, puede citarse a funcionarios municipales o distritales, con cinco días de anticipación, para que concurran al cabildo y para que respondan, oralmente o por escrito, sobre hechos relacionados con el tema del cabildo siendo la desatención inmotivada, causa de mala conducta. El cabildo abierto es el instrumento participativo más ejercitado en Colombia. En 2013 de 89 cabildos puestos en marcha 48 fueron aprobados, lo que supone un porcentaje del $54 \%{ }^{18}$.

\section{NOTAS SOBRE JURISPRUDENCIA CONSTITUCIONAL COMPARADA}

Dentro de la jurisprudencia constitucional más relevante quepa destacar en España la STC 103/2008, de 11 de septiembre, y en Colombia las sentencias C-180/1994, de 4 de abril, y la sentencia C-150/2015, de 8 de abril (por citar la primera y una de las más recientes en materia de democracia participativa). La jurisprudencia constitucional española, manifestada especialmente en la sentencia citada, más allá de diferenciar entre instrumentos participativos constitucionales y extra-constitucionales y considerar la democracia participativa como un complemento de la representativa, ha tenido por principal utilidad práctica diferenciar entre los referendos y las consultas populares, circunstancia especialmente relevante en España donde algunas Comunidades Autónomas (CCAA) han convocado o intentado convocar consultas populares que, sin embargo, fueron consideradas como referendos por el Tribunal Constitucional, el cual prohibió su realización y recordó que la autorización para la convocatoria de referendos corresponde en exclusiva al Estado y no a las

${ }^{18}$ Registraduría Nacional del Estado Civil, Cabildos abiertos 2013. Consultado, 03/03/2017, http://www.registraduria.gov.co/-Cabildo-abierto-.html. 
CCAA. Esta diferencia entre referendos y consultas, peculiar de España, viene motivada en gran medida por el deseo del constituyente de impedir que una determinada región asumiera una soberanía propia ajena a la nacional y preguntara a sus ciudadanos sobre una hipotética independencia, circunstancia ésta que precisamente ha estado cercana a producirse en las CCAA de Cataluña y del País Vasco mediante referendos que prohibió el Tribunal Constitucional. Básicamente, el Tribunal Constitucional consideró en esta sentencia que los referendos suponían una pregunta política al cuerpo electoral siguiendo el proceso y las garantías de los procesos electorales representativos. Sólo puede organizarlos el Estado. Por su parte las consultas eran preguntas a la ciudadanía que no cumplían esos requisitos, que podían convocar las regiones o los municipios y que, en la práctica, poseían una formalidad mucho menor.

La jurisprudencia constitucional colombiana sobre democracia participativa desde 1994 hasta el presente ha girado en todo momento alrededor de una serie de puntos tales como la consideración de la participación como uno de los elementos nucleares de todo el modelo constitucional surgido de 1991, herramienta para la profundización democrática y la creación de un verdadero estatus ciudadano democrático y participativo; entender la democracia participativa como un complementos, pero nunca como un substitutivo de la representación; utilizar la democracia participativa como una herramienta contra la corrupción y de control de la administración pública y para lograr una mayor eficiencia política. Se concibe la democracia participativa desde un punto de vista liberal (C-150/2015), más como un límite al poder del Estado, que como estrictamente un derecho de los ciudadanos, siendo su función la protección de las minorías frente a las mayorías. Tal vez lo más relevante de la jurisprudencia constitucional colombiana en esta materia sea que en los últimos veinte años se ha mantenido esencialmente uniforme.

\section{ALGUNAS MOTIVACIONES DE LA DEMOCRACIA PARTICIPATIVA EN ESPAÑA Y COLOMBIA}

Resulta de especial interés valorar los motivos que llevaron a esta regulación y jurisprudencia. Es decir, por qué el constituyente concibió una democracia participativa como la que configuró y no otra. Partiendo de una afirmación inicial, cual es que la práctica tanto española como colombiana de los instrumentos participativos es, en términos generales, escasa, aun y siendo la regulación colombiana más rica y 
variada, la pregunta es cuál fue la coyuntura constituyente de cada país que llevó a sus Cartas Magnas a ser redactadas como lo hicieron.

Respecto del caso español ${ }^{19}$, basta con revisar los debates constituyentes para comprobar que el Constituyente deseaba, tras el fin de la Dictadura y el comienzo de la democracia, crear un modelo esencialmente representativo construido alrededor de los partidos políticos, evitando toda posible tentación plebiscitaria (relativamente recurrente durante el Franquismo) y cualquier recurso al pueblo por parte de las fuerzas políticas extremistas (ya de izquierdas, ya de derechas) extraparlamentarias. Particularmente, el Constituyente español, en gran medida deudor del modelo constitucional italiano, trató de evitar algunas de las posibilidades de la democracia participativa italiana ${ }^{20}$, tales como el referendo derogatorio, sobre el cual se creó el prejuicio de que sería utilizado para frenar o incluso revertir las reformas democráticas que se llevaran a cabo por la mayoría parlamentaria. En este marco, es entendible que la Constitución de 1978, y derivada de ella tanto la legislación como la jurisprudencia constitucional, optaran por un modelo sumamente restrictivo con la democracia participativa que, como era previsible, apenas ha sido practicado.

El caso colombiano hay que entenderlo como hijo de la situación política colombiana a finales de los años ochenta y principios de los noventa. Tiempos en los que el Estado se enfrentaba a multitud de amenazas y que llevaron a que de un movimiento popular de origen universitario y juvenil (la Séptima Papeleta) surgiera la voluntad que finalmente fue del conjunto de la nación de no sólo reformar la Constitución de 1886, sino de, como corroboró la Corte Suprema, hacer una nueva mediante un proceso constituyente que, como no podía ser de otro modo teniendo la Constitución de 1991 ya en su génesis la participación, proclamó la democracia participativa como elemento nuclear del nuevo pacto constitucional ${ }^{21}$. Este

${ }^{19}$ Vide RAmíRez NÁRDIZ, A. (2009) El debate en torno a los mecanismos de democracia participativa durante el proceso constituyente español. Cuadernos constitucionales de la Cátedra Fadrique Furió Ceriol, núm. 67-68, págs. 167-178.

${ }^{20}$ Alzaga Villaamil, Ó. (1996) Derecho político español según la Constitución de 1978, Madrid: Edersa, págs. 295.

${ }^{21}$ «El proceso que condujo a la promulgación de la Constitución Política de 1991 fue producto de un anhelo nacional que deseaba una mayor participación política en las decisiones que los afectaban (...), lo que conllevó que la sociedad reaccionara, siendo el movimiento estudiantil su mayor exponente a través del movimiento conocido como la «Séptima Papeleta», el cual motivó a los gobiernos de Virgilio Barco y César Gaviria a diseñar los instrumentos jurídicos que permitieran una modificación a la Constitución Nacional de 1886.» Leiva-Ramírez, E. y Muñoz-GonzÁlez, A. L. (2011). El poder constituyente y la carta de derechos en la Constitución Política de Colombia de 1991. Administración y desarrollo, vol. 39, núm. 54, págs. 124-131. 
marco social e histórico explica la apuesta colombiana por la participación. ¿Pero por qué la práctica participativa es, sin embargo, tan escasa? La respuesta hay que buscarla en gran medida en la regulación derivada ${ }^{22}$, particularmente en los elevados porcentajes de participación y respaldo que impuso la Ley 134 y las dificultades que tanto estos porcentajes como los propios procesos determinados por la ley imponen a cualquier instrumento participativo para poder materializarse. Colombia es un país con una participación electoral que rara vez supera el 50\% y donde sus instrumentos participativos acostumbran a exigir apoyos elevados tanto en la convocatoria, como en la aprobación ${ }^{23}$. La prueba de que el propio legislador es consciente de esto se encuentra en las dos reformas legislativas efectuadas en 2002 y 2015 y en las que sucesivamente se han bajado estos porcentajes (por ej. en la revocatoria estas reformas han supuesto pasar de una participación mínima exigida de un $60 \%$ al actual $40 \%$ ) para permitir una más sencilla materialización de los diferentes instrumentos participativos. Se podría indicar que la decidida apuesta que la Constitución de 1991 hizo por la democracia participativa fue posteriormente moderada por la regulación derivada.

\section{CONCLUSIONES}

La regulación constitucional colombiana sobre democracia participativa es más amplia y rica que la española. Sin embargo, la práctica en ambos países, particularmente en el ámbito nacional, es decepcionante. En el caso español la explicación habría que buscarla

${ }^{22}$ También se puede argumentar que es en la propia Constitución en donde hay que buscar la respuesta a esta pregunta. Así MeJía Quintana considera que «Es necesario comenzar por recordar que la Constitución del 91 no cumplió la principal expectativa para la que fue convocada, a saber, el logro de la paz y (...) tampoco logró concretar lo que era otra de sus grandes aspiraciones: la de una auténtica y eficaz democracia participativa». MeJía-QuintanA, O. (2013) A dos décadas de la Constitución Política de 1991. Araucaria: revista iberoamericana de filosofía, política y humanidades, núm. 29, pág. 101.

${ }^{23}$ Buen ejemplo es la iniciativa legislativa popular, la cual, para iniciarse, necesita del apoyo de un 5\% del electorado. Parece un porcentaje pequeño, pero, si se piensa que el electorado colombiano lo componen 34-35 millones de ciudadanos, la iniciativa ha de tener un respaldo de entre 1.7 y 1.8 millones de personas. España, con una población apenas algo menor a la colombiana, exige 500.000 firmas para iniciar el proceso. Es decir, en Colombia son necesarios el triple de apoyos que en España para que una iniciativa legislativa popular dé comienzo. 
en las motivaciones del constituyente, mucho más interesado en asegurar una democracia representativa estable alrededor de los partidos políticos, que en promover la participación directa de los ciudadanos en la vida política. En el caso colombiano, si bien la Constitución apostó por la participación y la jurisprudencia así lo ha corroborado, la legislación limitó estas aspiraciones participativas y configuró un modelo en el que, en la práctica, la participación directa ha sido escasa.

El futuro desarrollo de la democracia participativa en los dos países depende tanto de las líneas jurisprudenciales de ambas cortes constitucionales, como, especialmente, del desarrollo legislativo. Si esto es así, el caso colombiano resulta más esperanzador, pues la dinámica de las reformas ha sido hasta el presente la de facilitar la participación directa (lo cual no implica que ésta sea ya sencilla), mientras que en el caso español la regulación inicial se mantiene esencialmente intacta, siendo además más difícil de ampliar por ser el listado de instrumentos participativos recogidos en la Constitución más breve en el caso español que en el colombiano.

No hay que olvidar que la experiencia nacional colombiana con instrumentos como el referendo o el plebiscito ha sido sumamente frustrante, no consiguiéndose el respaldo popular en ninguna de las dos grandes preguntas que se plantearon a los ciudadanos en las últimas dos décadas, mientras que en España los resultados de los referendos han sido positivos para el gobierno convocante. No tiene por qué significar esto que en España se vaya a apostar por realizar nuevas preguntas a la ciudadanía (en Colombia es más que probable que no se vuelva a hacer, como bien demostró el que los acuerdos de paz con las FARC, una vez modificados, no se volvieran a someter a plebiscito, sino que se aprobaran en sede parlamentaria), pues si algo ha demostrado la experiencia reciente con casos como el plebiscito colombiano, pero también el referendo británico o el italiano, es que, en tiempos complejos, las preguntas a la ciudadanía más que beneficios, pueden aportar grandes perjuicios a los gobiernos convocantes.

En cualquier caso, en ninguno de los dos países, a salvo de que se redacten nuevas Constituciones, y viendo la estabilidad legislativa de las últimas décadas, parece previsible un cambio regulatorio radical a favor (o en contra) democracia participativa, lo cual no puede llevar más que a concluir que al actual statu quo de la democracia participativa se mantendrá en el futuro inmediato. 


\section{BIBLIOGRAFÍA}

\section{Doctrina}

Alzaga VillaAmil, Ó. Derecho politico español según la Constitución de 1978. Madrid: Edersa. 1996.

BBC Colombia. Confirmada derrota en referendo. Consultado, 02/03/2017. news.bbc.co.uk/hi/spanish/specials/2003/balance_2003/newsid_3364000/3364751.stm. 2003.

Canales Aliende, J. M. La democracia participativa local, Sistema, Revista de ciencias sociales, núm. 184-185, págs. 191-201. 2005.

Cotino HuEso, L. La regulación de la participación y de la transparencia a través de internet y medios electrónicos. Propuestas concretas, P3T Journal of public policies and territories, núm. 2, vol. 1. 2012.

Fernández-Miranda, C. y Fernández-Miranda, A. Sistema electoral, partidos políticos y parlamento. Madrid: Colex. 2003.

Garcés Villamil, M. A. y Rapalino Bautista, W. G. La consulta popular como mecanismo de participación ciudadana para evitar actividades mineras, Justicia Juris, vol. 11, núm. 1, págs. 52-62. 2015.

Habermas, J. Facticidad y validez. Sobre el derecho y el Estado democrático de derecho en términos de teoría del discurso. Madrid: Trotta. 1998.

Kelsen, H. Esencia y valor de la democracia, Madrid: Guadarrama. 1977.

LeIVA-RamíRez, E. y MuÑoz-GonZÁLEZ, A. L. El poder constituyente y la carta de derechos en la Constitución Política de Colombia de 1991. Administración y desarrollo, vol. 39, núm. 54, págs. 119-132. 2011.

Mejía-Quintana, O. A dos décadas de la Constitución Política de 1991. Araucaria: revista iberoamericana de filosofía, política y humanidades, núm. 29, págs. 99-116. 2013.

RAMírez NÁRDIZ, A. Guía práctica de la democracia participativa. Conocer la democracia participativa y aprender a usarla, Madrid: Dykinson. 2012.

- «El debate en torno a los mecanismos de democracia participativa durante el proceso constituyente español». Cuadernos constitucionales de la Cátedra Fadrique Furió Ceriol, núm. 67-68, págs. 167-178. 2009. 
Registraduría Nacional del Estado Civil, Plebiscito 2 de octubre de 2016. Consultado, 24/03/2017, http://plebiscito.registraduria.gov.co/

- Iniciativa legislativa y normativa, histórico de iniciativas. Consultado, 03/03/2017. www.registraduria.gov.co/-Historico-de-iniciativas-.html.

- Cabildos abiertos 2013. Consultado, 03/03/2017, http://www.registraduria.gov.co/-Cabildo-abierto-.html.

- Ranking de mecanismos de participación por departamentos. Consultado 04/03/2017. www.registraduria.gov.co/-Mecanismos-deParticipacion,320-.html.

Schumpeter, J. A. (1971) Capitalismo, socialismo y democracia. Madrid: Aguilar.

Thomas-Acuña, E. (2008) Colombia: entre la crisis de la representatividad y la democracia directa. Zurich: C2D.

\section{Legislación}

Colombia. Constitución Política de 1991.

Colombia. Ley 131 de 1994 (mayo 9), por la cual se reglamenta el voto programático y se dictan otras disposiciones.

Colombia. Ley 134 de 1994 (mayo 31), por la cual se dictan normas sobre mecanismos de participación ciudadana.

Colombia. Ley 741 de 2002 (mayo 31), por la cual se reforman las Leyes 131 y 134 de 1994, Reglamentarias del voto programático.

Colombia. Ley 1757 de 2015 (julio 06), por la cual se dictan disposiciones en materia de promoción y protección del derecho a la participación democrática.

Colombia. Ley Estatutaria 1806 de 2016 (agosto 24), por medio de la cual se regula el plebiscito para la refrendación del acuerdo final para la terminación del conflicto y la construcción de una paz estable y duradera.

España. Constitución española de 1978.

España. LO 2/1980, de 18 de enero, sobre regulación de las distintas modalidades de referéndum.

España. LO 3/1984, de 26 de marzo, reguladora de la iniciativa legislativa popular. 
España. LO 5/1985, de 19 de junio, del Régimen Electoral General.

España. Ley 7/1985, de 2 de abril, reguladora de las Bases del Régimen Local.

España. LO 2/2011, de 28 de enero, por la que se modifica la Ley Orgánica 5/1985, de 19 de junio, del Régimen Electoral General.

España. LO 4/2006, de 26 de mayo, de modificación de la Ley Orgánica 3/1984, de 26 de marzo, reguladora de la Iniciativa Legislativa Popular.

\section{Jurisprudencia}

Colombia. Sentencia C-180/1994, de 4 de abril.

Colombia. Sentencia C-150/2015, de 8 de abril.

España. STC 103/2008, de 11 de septiembre. 
